\title{
CARACTERIZAÇÃO FÍSICO-QUÍMICA E MICROBIOLÓGICA DO LEITE DE BÚFALA “IN NATURA" PRODUZIDO NO ESTADO DO PARÁ
}

\section{PHYSICAL-CHEMICAL AND MICROBIOLOGICAL CHARACTERIZATION OF BUFFALO MILK "IN NATURA" PRODUCED IN THE STATE OF PARA}

\author{
Elaine Lopes Figueiredo ${ }^{1}$; José de Brito Lourenço Junior ${ }^{2}$; Maricely Janete Uria Toro ${ }^{3}$ \\ ${ }^{1}$ Universidade do Estado do Pará - UEPA - Belém - Brasil lane figueiredo@ yahoo.com.br \\ ${ }^{2}$ Empresa Brasileira de Pesquisa Agropecuária - EMBRAPA - Belém - Brasil lourenco@ amazon.com.br \\ ${ }^{3}$ Universidade do Estado do Pará - UEPA - Belém - Brasil maruria@ bol.com.br
}

\begin{abstract}
Resumo
A exploração dos bubalinos para a produção de leite e elaboração de seus derivados é uma atividade que tem crescido nos últimos anos no Brasil, particularmente no Estado do Pará. $O$ objetivo do trabalho foi avaliar as características físico-químicas e microbiológica do leite de búfala produzido no Estado do Pará. As amostras foram obtidas de dois diferentes rebanhos, localizados na cidade de Belém (Local A) e o outro em Soure, na Ilha do Marajó (Local B), no Pará. Foram determinados os níveis de umidade, lipídeo, ácido linoléico conjugado (CLA), proteína, resíduo mineral fixo, carboidrato, acidez, $\mathrm{pH}, e$ o valor calórico. As análises microbiológicas foram contagem padrão de bactérias aeróbias mesófilas, bolores e leveduras, coliformes a $35^{\circ} \mathrm{C}$ e $45^{\circ} \mathrm{C}$, Staphylococus aureus e Salmonella. As médias das variáveis físicoquímicas indicaram que essa matéria-prima apresenta níveis elevados de lipídeos, proteinas e de valor calórico. Os níveis encontrados de ácido linoléico conjugado - CLA mostraram a importância dessa matéria-prima para a alimentação. No que se refere aos resultados microbiológicos, nenhuma amostra de leite apresentou fora dos padrões exigidos pela legislação vigente, não apresentando assim contaminação por contaminação por coliformes a $45^{0} \mathrm{C}$, Staphylococcus aureus e Salmonella.
\end{abstract}

Palavras-chave: leite de búfala, características, qualidade.

\section{Introdução}

A produção leiteira se destaca como uma das principais aptidões das búfalas e é considerada de grande importância em vários países. Na Ásia, o búfalo tem papel fundamental na agricultura, podendo ser criado em pequenas propriedades rurais, onde é considerado o principal provedor de alimentos. $\mathrm{Na}$ Índia, embora o rebanho bubalino seja somente $24 \%$ do rebanho total de bovinos e bubalinos, cerca de $60 \%$ do leite produzido nesse país é de búfala. No Brasil, sua contribuição 
também é de grande importância em pequenas e médias propriedades rurais, onde é considerado o principal provedor de alimentos, garantindo a produtividade e a permanência sustentável do homem na zona rural (AMARAL et al., 2005; NASCIMENTO; MOURA CARVALHO, 1993).

O leite de búfala apresenta características que o diferenciam de qualquer outro tipo de leite. Seus valores de lipídeos, proteínas, lactose, sólidos totais, e resíduo mineral fixo, são de grande importância nutricional. A ausência do $\beta$-caroteno na composição química do leite de búfala é uma de suas características mais marcantes, conferindo-lhe coloração branca. É importante ressaltar que a ausência dessa substância, não é considerada um problema nutricional, por esse alimento ser considerado um precursor de vitamina A. É mais concentrado do que o leite bovino, apresentando assim menos água e mais matéria seca. Outra característica importante é que possui um sabor bem adocicado, apesar de não possuir mais lactose que o leite bovino. Seu alto teor de cálcio faz com que seja recomendado contra osteoporose. É vital no processo de recuperação de pacientes, em luta contra doenças de todos os tipos, que precisam ingerir alimentos de qualidade em pequenas doses ao longo do dia (DUBEY, 1997; MACEDO et al., 2001).

A gordura é o constituinte do leite que apresenta maior valor econômico, sendo utilizada na produção de derivados. Contribui para o sabor característico do leite e seus derivados, e melhora a textura. Sob o ponto de vista nutricional, os lipídeos apresentam níveis apreciáveis de ácidos graxos essenciais ao organismo. A proporção de ácido graxo saturado/ácido graxo polinsaturado é considerada nutricionalmente correta. O leite de búfala possui o dobro de ácido linoléico conjugado (CLA) do que o leite de vaca. O CLA é um componente característico da gordura presente no tecido adiposo de ruminantes, o qual é formado no rúmen como intermediário da biohidrogenação do ácido linoléico isomerase (ELIAS et al., 2004). Descreve um ou mais isômeros posicional e geométrico do ácido linoléico (cis-9, cis-12, ácido octadecadienóico), contendo duplas ligações conjugadas. Tais ligações encontram-se nas posições 9 e 11 ou 10 e 12, podendo ser de configuração cis ou trans. É uma substância anticancerígena e atua, também, sobre os efeitos secundários da obesidade, da arteriosclerose e da diabete (OLIVEIRA, 2004).

Além do fato de na composição do leite estar presentes muitos nutrientes essenciais para a dieta humana, sua flora microbiana natural torna esse alimento um excelente meio para o crescimento de microrganismos, o faz com que esse alimento seja de grande perecibilidade, necessitando de procedimentos tecnológicos adequados, capazes de garantir sua integridade e proteger sua capacidade como matéria-prima essencial para a produção de derivados (AMARAL et al., 2005; FREITAS, 2001; GONÇALVES;VIEIRA, 2002).

Os microrganismos presentes no leite provêm de diversas fontes. A primeira contaminação ocorre no úbere do animal, e a quantidade de microrganismo presente no leite depende do estado de 
saúde do animal e das condições de higiene no momento da ordenha. O leite recém-ordenhado, dentro de limites, possui propriedades germicidas, devido às lacteninas, consideradas inibidoras de bactérias. Após a ordenha, a matéria-prima pode ser transportado, em até três horas, para a plataforma de recepção da indústria, sem problemas microbianos. Porém, essa ação antimicrobiana temporal tem pouca importância nos métodos modernos de manipulação do leite. A proliferação microbiana será inevitável, a menos que o leite seja armazenado sob temperatura de congelamento. Embora o desenvolvimento microbiano seja lento na temperatura entre 0 a $5^{\circ} \mathrm{C}$, ainda podem ocorrer mudanças indesejáveis, que dependem do tipo e da quantidade de microrganismo presente. Por outro lado, apesar dos tratamentos térmicos destruírem vários tipos de bactérias, suas enzimas permanecem ativas e podem originar modificações inconvenientes nos derivados (MACEDO et al., 2001; SÁ, 2004; VIEIRA et al., 1994).

$\mathrm{Na}$ indústria de lacticínios devem ser exercidas tecnologias adequadas de fabricação. Ao lado do aporte tecnológico, representado principalmente pela adoção de práticas higiênicas, implementação de mudanças na área tecnológica da produção, métodos adequados de conservação, e inovação na produção de derivados, as indústrias devem incorporar e tornar parte obrigatória o sistema de controle de qualidade (FREITAS, 2001; GONÇALVES; VIEIRA, 2002).

A qualidade do leite é o fator mais importante para o sucesso de sua industrialização e de seus derivados, pois interessa tanto aos laticínios, o que gera aumento significativo no preço do leite, e aos consumidores, que por sua vez, adquirem produtos de melhor qualidade.

Assim, este trabalho tem como objetivo avaliar a qualidade físico-química e microbiológica do leite de búfala, de dois diferentes rebanhos, localizados na cidade de Belém e o outro em Soure, na Ilha do Marajó, no Pará.

\section{Material e Métodos}

\section{Coleta de amostras}

Foram coletadas amostras de leite de búfala $(100 \mathrm{~mL})$, de animais da raça Murrah, procedentes de dois rebanhos, um localizado em Belém-Pa (Local A) e o outro em Soure, na Ilha do Marajó-Pa (Local B). De cada local, foram coletadas 10 amostras de leite, totalizando 20 amostras. As amostras foram acondicionadas em caixa de isopor com gelo e enviadas ao Laboratório de Físico-Química e de Microbiologia, do Centro de Ciências Naturais e Tecnologia - CCNT, da Universidade do Estado do Pará - UEPA. Foram analisadas amostras, quanto aos parâmetros físicoquímicos e microbiológicos, e comparadas com os padrões estabelecidos pelas legislações vigentes. 


\section{Análises físico-químicas}

Foram realizadas análises físico-químicas de umidade, lipídeo, ácido linoléico conjugado CLA, proteína bruta, resíduo mineral fixo, carboidrato, acidez, $\mathrm{pH}$, além do cálculo de valor calórico. Todas as análises seguiram a metodologia preconizada por Instituto Adolpho Lutz (2005).

A determinação de umidade foi realizada, em estufa, a $105^{\circ} \mathrm{C}$, até peso constante. Para a determinação do teor de lipídeos foi utilizado o método butirométrico de Gerber. Os níveis de Ácido Linoléico Conjugado - CLA, foram obtidos através da metodologia HPLC. O nitrogênio total foi determinado pelo método Kjeldahl. Para determinar os níveis de resíduo mineral fixo, transferiram-se $20 \mathrm{~mL}$ de leite para uma cápsula de porcelana, previamente aquecida, em mufla, sob temperatura de $550{ }^{\circ} \mathrm{C}$, por aproximadamente uma hora, sendo resfriada em dessecador, para pesagem, até peso constante. O teor de carboidrato foi obtido pela diferença entre 100 e a somatória dos níveis de proteína, lipídeos, umidade e cinzas. A acidez titulável foi obtida pelo método Dornic. $\mathrm{O}$ pH foi determinado em potenciômetro. O valor calórico foi obtido pela somatória dos teores de carboidratos e proteínas, multiplicados por quatro, e de lipídeos, multiplicados por nove, de acordo com os coeficientes de Atwater.

\section{Análises microbiológicas}

As análises microbiológicas foram contagem padrão de bactérias aeróbias mesófilas, contagem de bolores e leveduras, coliformes a $35^{\circ}$ e a $45^{\circ} \mathrm{C}$, contagem de Staphylococcus aureus e pesquisa de salmonelas. As determinações microbiológicas foram realizadas seguindo os métodos analíticos oficiais exigidos pelo Ministério da Agricultura, e Agência Nacional de Vigilância Sanitária - ANVISA, Resolução nº 12, de 2 de janeiro de 2001 (BRASIL, 2001).

Para a contagem de bactérias aeróbias mesófilas, empregou-se o método de contagem padrão em placas, com semeadura em meio de cultura Agar Padrão para Contagem (PCA), com incubação sob temperatura de $37^{\circ} \mathrm{C}$, por 24 a 48 horas. Os bolores e leveduras foram determinados por semeio em batata-glucose-agar acidificado, em placas incubadas, a $21^{\circ} \mathrm{C}$, durante cinco dias.

A determinação de coliformes $35^{\circ} \mathrm{C}$ e a $45^{\circ} \mathrm{C}$ foi realizada pela técnica dos tubos múltiplos $\left(10^{-1}, 1\right.$ e 10). Empregou-se, como meio presuntivo, o Caldo Lauril Sulfato Triptose, com incubação a $35^{\circ} \mathrm{C}$, por 48 horas. Após leitura, os tubos positivos foram repicados para Caldo Verde Brilhante bile, a $2 \%$ de lactose, para confirmação da presença de coliformes a $35^{\circ} \mathrm{C}$, e repicados para "Caldo EC", visando a confirmação de coliformes a $45^{\circ} \mathrm{C}$. 
Para a avaliação de Staphylococcus aureus, as amostras foram inoculadas em meio Agar Baird-Parker, enriquecido com gema de ovo e telurito, sob temperatura de $35^{\circ} \mathrm{C}$, por 24 a 48 horas. Para a pesquisa de Salmonella, utilizou-se $225 \mathrm{~mL}$ de água tamponada e $25 \mathrm{~mL}$ de leite, sob temperatura de $35^{\circ} \mathrm{C}$, por 24 horas. Em seguida, transferiu-se alíquotas de $1 \mathrm{~mL}$ dessa suspensão para $100 \mathrm{~mL}$ de Caldo Selenito Cistina (SC) e $1 \mathrm{ml}$ para $10 \mathrm{~mL}$ de Caldo Tetrationato (CT) e incubados a $35^{\circ} \mathrm{C}$, por 24 horas. Após esse período, realizaram-se semeaduras, em placas de Petri, contento Ágar Entérico de Hectoen (HE), Agar Bismuto Sulfito (BS), Agar Xilose Lisina (XLD), Agar Verde Brilhante (VB) e Agar Salmonella - Shigella (SS) (método de Plaqueamento diferencial). Repetiu-se esse procedimento para o Caldo SC, incubando as placas invertidas a $35^{\circ} \mathrm{C}$ por 24h. Após esse tempo verificou-se o crescimento de colônias típicas de Salmonella spp. O teste bioquímico para confirmação foi realizado com o auxílio de uma alça em agulha de inoculação, onde foi removida uma porção da massa de célula, do centro da colônia típica de Salmonella e inoculou-se em tubos contendo Ágar Lisina Ferro (LIA), Ágar Tríplice de Açúcar Ferro (TSI), Caldo Ureia e Caldo Malonato, incubando-se em estufa a $35^{\circ} \mathrm{C}$ por $24 \mathrm{~h}$.

\section{Resultados e Discussões}

\section{Análises Físico-Químicas do Leite de Búfala "in natura”}

As médias dos resultados das análises físico-químicas das amostras de leite de búfala estão apresentados na Tabela 1, onde pode ser observada a similaridade estatística entre os valores das determinações dos dois locais avaliados.

Tabela 1. Teores médios das variáveis físico-químicas de leite de búfala, em dois locais.

\begin{tabular}{lccc}
\hline \multicolumn{1}{c}{ Determinação } & Local A & Local B & Probabilidade \\
\hline Umidade (\%) & $81,99 \pm 0,75$ & $81,91 \pm 0,33$ & $0,8334^{(1)}$ \\
Lipídeos (\%) & $8,14 \pm 0,66$ & $8,22 \pm 0,29$ & $0,8112^{(1)}$ \\
Ácido Linoléico Conjugado - CLA & $0,12 \mathrm{~g} / 100 \mathrm{~g} \pm 0,31$ & $0,13 \mathrm{~g} / 100 \mathrm{~g} \pm 0,22$ & $0,8278^{(1)}$ \\
Proteína (\%) & $4,44 \pm 0,21$ & $4,39 \pm 0,14$ & $0,7130^{(1)}$ \\
Carboidrato (\%) & $4,55 \pm 0,92$ & $4,43 \pm 0,37$ & $0,7973^{(1)}$ \\
RMF (\%) & $0,95 \pm 0,04$ & $0,95 \pm 0,004$ & $0,2800^{(2)}$ \\
Acidez ( $\left.{ }^{\circ} \mathrm{D}\right)$ & $17,89 \pm 0,39$ & $18,13 \pm 0,53$ & $0,4344^{(1)}$ \\
pH & $6,48 \pm 0,14$ & $6,46 \pm 0,08$ & $0,9900(2)$ \\
Valor calórico (Kcal/100g) & $109,83 \pm 4,8$ & $109,29 \pm 2,56$ & $0,8288(1)$ \\
\hline
\end{tabular}

(1) - Teste de Normalidade, de Shapiro-Wilk. (2) - Teste Não Paramétrico, de Wilcoxon.

Os teores de umidade no leite de búfala (81,99\% - Local A e 81,91\% Local B) aproximamse dos citados por Teixeira et al. (2005), de 81,9\%, por Huhn et al. (1991), de 82,5\%, por Neves (2002), de 82,21\% a 82,93\%. As médias dos lipídeos (8,14\% - Local A e 8,22\% - Local B) comprovam o alto nível de gordura desta matéria-prima, o que favorece decisivamente para o 
aumento do rendimento na fabricação de derivados como o queijo. Os resultados encontrados assemelham-se aos reportados por Yang et al. (2006), de 8,18\% a 8,26\%, e Huhn et al. (1991), de $8,0 \%$. No entanto, Neves (2002) e Macedo et al. (2001) encontraram valores inferiores (6,0\% e 6,59\%, respectivamente) aos deste trabalho. Segundo Amaral et al. (2005), essas diferenças são provocadas por influências de fatores ambientais, como estação de ano e nutrição, e efeitos do animal, como raça, idade, e estágio de lactação. A aproximação entre os valores encontrados neste trabalho pode estar relacionada principalmente ao fato de as búfalas dos Locais A e B possuírem a mesma dieta nutricional.

Os níveis de Ácido Linoléico Conjugado - CLA encontrados foram de 0,12 g/100g para o Local A e 0,13 g/100g para o Local B. Ao avaliar os níveis de CLA no leite de búfalas, Van Nieuwenhove et al. (2004) observaram teor de 0,48\% de CLA no leite de búfalas. O CLA é uma substância anticancerígena e atua, também, sobre os efeitos secundários da obesidade, arteriosclerose e da diabete. Alguns estudos sobre os benefícios do CLA comprovam que a sua adição na dieta alimentar das pessoas produz reduções significativas de tumores (ELIAS et al., 2004).

Os teores de proteína também são influenciados por fatores ambientais e nutricionais, como a alimentação com diferentes níveis e fontes de nitrogênio, além da disponibilidade de energia. Neste trabalho, os valores médios de proteína, de 4,44\%, no Local A, e 4,39\%, no Local B, estão próximos aos obtidos por Zen et al. (2006), de 4,40\%, por Neves (2002), de 4,26\% e por Macedo et al. (2001), de 4,23\%. Na China, também em leite de búfalas da raça Murrah, Yang et al. (2006) encontraram valores entre $4,97 \%$ e $5,15 \%$.

Os níveis de carboidrato, 4,55\%, para o Local A e 4,43\%, para o Local B, se assemelham aos de Neves (2002), de 4,33\% e são inferiores aos encontrados por Prudêncio et al. (2003), de $5,47 \%$, no leite de búfalas Murrah.

A média ajustada de acidez titulável $\left(17,89^{\circ} \mathrm{D}\right.$ - Local A e $18,13^{\circ} \mathrm{D}$ - Local B), é inferior à encontrada por Macedo et al. (2001), de 18,98 D, e superior à determinada por Huhn et al. (1991), de $17^{\circ} \mathrm{D}$. As variações na acidez titulável podem estar relacionadas ao excesso de forragem grosseira, sem observação de características nutricionais, fornecimento de alimentos e minerais inapropriados, silagens de baixa qualidade, além de fatores ambientais. Segundo Oliveira et al. (2003), a acidez elevada no leite pode ser resultado da acidificação da lactose, provocada pela multiplicação de microrganismos deterioradores e/ou patogênicos.

As médias encontradas para os valores de pH (6,48 no Local A e 6,46 no Local B), estão dentro da faixa considerada ideal, ou seja, valores de pH de leite normal ficam entre 6,43 a 6,82. Segundo Freitas Filho et al. (2009) estes níveis de pH são um indicador da qualidade sanitária e da 
estabilidade térmica do leite. As médias encontradas neste trabalho aproximam-se das encontradas por Neves (2002), de 6,55 a 6,70 e Prudêncio et al. (2003), de 6,55.

\section{Análises Microbiológicas do Leite de Búfala "in natura”}

Todas as amostras de leite apresentaram proliferação de bactérias aeróbias mesófilas e bolores e leveduras. Essa contaminação, possivelmente, foi resultante de falhas higiênico-sanitárias na ordenha, nos animais, e/ou no ambiente, apesar da utilização de Boas Práticas de Produção na obtenção da matéria-prima. É importante destacar que o produto “in natura" é um dos alimentos mais perecíveis e não foi submetido a nenhum tratamento térmico antes das análises. Tagami et al. (2005), ao analisar a microbiota do leite cru, verificou que 43,7\% das amostras possuíam elevadas contaminações desses microrganismos.

As médias dos resultados das análises microbiológicas das amostras de leite de búfala, dos dois locais avaliados podem ser observadas na Tabela 2.

Tabela 2. Resultados das médias das análises microbiológicas do leite de búfala "in natura".

\begin{tabular}{lcc}
\hline \multicolumn{1}{c}{ Determinação } & Local A & Local B \\
\hline Bactérias aeróbias mesófilas (UFC/mL) & $10^{4}$ & $3,2 \times 10^{4}$ \\
Bolores e Leveduras (UFC/mL) & $1,5 \times 10^{3}$ & $1,6 \times 10^{3}$ \\
Coliformes a $35^{\circ} \mathrm{C}(\mathrm{NMP} / \mathrm{mL})$ & 1,5 & 0,91 \\
Coliformes a $45^{\circ} \mathrm{C}(\mathrm{NMP} / \mathrm{mL})$ & $<0,3$ & $<0,3$ \\
Staphylococus aureus $(\mathrm{UFC} / \mathrm{mL})$ & ausência & ausência \\
Salmonella $(\mathrm{em} 25 \mathrm{~mL})$ & ausência & ausência \\
\hline
\end{tabular}

Foi observada contaminação por coliformes a $35{ }^{\circ} \mathrm{C}$, em apenas $20 \%$ das amostras analisadas, e em pequenos números de células viáveis em cada uma dessas amostras. Fato similar foi observado por Yang et al. (2006). Os coliformes a $35^{\circ} \mathrm{C}$ são considerados microrganismos indicadores de contaminação e, quando encontrados no leite, denunciam problemas higiênicosanitários na obtenção do leite e/ou na qualidade inferior da água (LANDGFRAF, 2008).

Não foram detectadas contaminações de coliformes a $45^{\circ} \mathrm{C}$, Staphylococcus aureus e Salmonella no leite de búfala, nos dois locais estudados. De acordo com a Agência Nacional de Vigilância Sanitária - ANVISA, e Ministério da Agricultura, Portaria nº12, de 2 de janeiro de 2001, o limite máximo permitido para microrganismos presentes em leite pasteurizado é: Salmonellas ausência em $25 \mathrm{~mL}$, e coliformes a $45^{\circ} \mathrm{C}(\mathrm{NMP} / \mathrm{mL})$ - $4 \mathrm{NMP} / \mathrm{mL}$. Assim, pode-se afirmar que a matéria-prima apresentava-se dentro dos padrões microbiológicos exigidos, apesar de ainda não ter sido submetida à pasteurização (BRASIL, 2001). 


\title{
4. Conclusão
}

De acordo com as análises físico-químicas, pode-se dizer que o leite de búfala, dos dois locais avaliados, apresentou níveis elevados de lipídeos, proteína e valor calórico, o que confirma que essa matéria-prima possui uma grande riqueza nutricional. Por outro lado, os altos níveis de lipídeos favorecem ainda para o aumento do rendimento na elaboração de derivados. Os níveis de Ácido Linoléico Conjugado confirmam a importância dessa matéria-prima para o consumo humano, ajudando a combater doenças como a obesidade e a diabete.

A avaliação microbiológica indicou que o leite de búfala estava de acordo com a legislação vigente, para leite pasteurizado, apesar da detecção de contagens de microorganismos, o que não acarreta impedimento na sua comercialização, visando o consumo humano.

\begin{abstract}
The exploitation of buffaloes for milk production and preparation of derivatives is an activity that has grown in recent years in Brazil, particularly in the state of Pará. The objective of this study was to evaluate the physical-chemical and microbiological quality of buffalo milk produced State of Pará. Samples were obtained from two different herds located in the town of Belém (site A) and the other in Soure in Marajó, (Site B), in Pará. Were determined levels of humidity, lipid, conjugated linoleic acid (CLA), protein, ash, carbohydrate, acid, $\mathrm{pH}$, and caloric value. Microbiological tests were standard score of mesophylla aerobic bacteria, molds and yeasts, coliforms at $35{ }^{\circ} \mathrm{C}$ and 45 ${ }^{\circ} \mathrm{C}$, Staphylococcus aureus and Salmonella sp. The mean physical and chemical variables indicated that this material has high levels of lipids, proteins and calories. The levels found of conjugated linoleic acid - CLA showed the importance of this raw material for food. With regard to microbiological results, no milk sample showed non-standard required by law and that it had contamination by fecal contamination to $45^{\circ} \mathrm{C}$, Staphylococcus aureus and Salmonella.
\end{abstract}

Key-words: buffalo milk, features, quality

\section{Referências}

AMARAL, F. R.; CARVALHO, L. B.; SILVA, N. et al. Qualidade do leite de búfalas: composição. Revista Brasileira de Reprodução Animal, v.29, p.106-110, 2005.

BRASIL, Agência Nacional de Vigilância Sanitária - ANVISA. Resolução - RDC n. 12, de 2 de janeiro de 2001. Ministério da Saúde, 2001.

DUBEY, P. C.; SUMAN, C. L.; SANYAL, M. K. et al. (sic) Factors affecting composition of milk of buffaloes. Indian Journal of Animal Sciences, v. 67, n. 9, p. 802-804, 1997.

ELIAS, A.H.N, et al.(sic) Ácido linoléico conjugado (CLA) na mussarela de búfalas. In: Congresso Brasileiro de Ciência e Tecnologia de Alimentos, 19. Recife, 2004.

FREITAS FILHO, J. R., SOUZA FILHO, J.S., OLIVEIRA, H.B., ANGELO, J.H.B., BEZERRA, J.D.C. Avaliação da qualidade do queijo "coalho" artesanal fabricado em Jucati - PE. Revista Eletrônica de Extensão, v. 6, n. 8. 2009. Disponível em: www.periodicos.ufsc.br.

FREITAS, J.A. Qualidade do leite frente seu beneficiamento e obtenção de derivados. In: Seminário de Zootecnia, I. 2001, Belém-Pará. Faculdade de Ciências Agrárias do Pará. Belém, set. 2001. 
GONÇALVES, C.A., VIEIRA, L.C. Obtenção e higienização do leite in natura. Empresa Brasileira de Pesquisa Agropecuária, Embrapa Amazônia Oriental, Belém: Documento 141. 2002. 28p.

INSTITUTO ADOLPHO LUTZ. Normas Analíticas do Instituto Adolfo Lutz: Métodos Químicos para Análise de Alimentos. 2.ed. São Paulo: Instituto Adolfo Lutz, 2005. 533p.

HÜHN, S., LOURENÇO JUNIOR, J. B., MOURA CARVALHO, L. O. D., NASCIMENTO, C. N. B., VIEIRA, L. C. Características, peculiaridades e tecnologia do leite de búfalas. Belém: EMBRAPA - CPATU, 1991. 51p. (EMBRAPA - CPATU. Documentos, 57).

LANDGRAF, M. Microrganismos Indicadores. In: FRANCO, B.D.G., LANDGRAF, M.: Microbiologia dos alimentos. São Paulo. Atheneu, 2008, p.27-31.

MACEDO, M. P., WECHSLER, F. S., RAMOS, A. A., AMARAL, J. B, SOUZA, J. C., RESENDE, F. D., OLIVEIRA, J. V. Composição físico-química e produção do leite de búfalas da raça Mediterrâneo no Oeste do Estado de São Paulo. Revista Brasileira de Zootecnia. Viçosa. v. 30, n. 3. sup. 1, mai. 2001.

NASCIMENTO, C. N. B., MOURA-CARVALHO, L.O.D. Criação de búfalos: alimentação, manejo, melhoramento e instalações. EMBRAPA-CPATU. Brasília: EMBRAPA-SPI, 1993. 403p.

NEVES, E. C. A Recent progress concerning buffalo milk technology in Amazon-Brazil. In: Buffalo Symposium of Américas, 1. 2002, Belém, 2002. p. 312-316.

OLIVEIRA, R. L. Ácidos graxos de cadeia longa (CLA) no leite e seus benefícios para o consumo. In: Congresso Nacional de Zootecnia, 14. Brasília, 2004.

PRUDÊNCIO, E. S., MAGENIZ, R. B., FALCÃO, L. D., OLIVEIRA, M. C. L., PRUDÊNCIO, I. D., FALCÃO, A. P., AMANTE, E. R., LUIZ, M. T. B. Estudo do processo de microfiltração do leite de búfala (bubalus bubalis) desnatado. In: Simpósio Latino Americano de Ciência de Alimentos - SLACA, 5., 2003, Unicamp, Campinas, nov. 2003.

SÁ, E. Análises realizadas para o controle da qualidade de leite in natura de acordo com os parâmetros legais. Revista Leite \& Derivados, ano XIV, n. 81, p. 67-72. 2004.

TAGAMI, P. M., DAMIAN, N., TAKAHASHI, H. T., FALCONI, F. A. Avaliação da qualidade do leite cru e submetido à fervura convencional comercializado informalmente no município de Cascavel - PR. In: Simpósio Latino Americano de Ciência de Alimentos, 6. 2005. Unicamp, Campinas, nov. 2005.

TEIXEIRA, L.V., BASTIANETTO, E., OLIVAR, P.A.A. Leite de Búfala na Indústria de Produtos Lácteos. Revista Brasileira de Reprodução Animal. Belo Horizonte, n.2. abr./jun. 2005. p.96-100.

VAN NIEUWENHOVE; GONZÁLEZ, S.; PÉREZ CHAIA, A. Conjugated linoleic acid in buffalo (Bubalus bubalis) milk from Northwest Argentina. Milchwissenschaft, v. 59, p. 506-508, 2004.

VIEIRA, L. C., LOURENÇO JUNIOR, J. B., HUHN, S., BATISTA, H. A. M., HANTANI, A. K. Microbiology of buffalo milk under different hygienic conditions. In: WORLD BUFFALO CONGRESS, 4, 1994, São Paulo. Anais. São Paulo: ABCB/IBF/FAO/FINEP, v. 2, p.174-176, 1994.

YANG, Y. X., DONG, X. F., LI, L. L., REN, F. Z., HAN, B. Z. Analysys of the microbiological and chemical composition of buffalo milk in Yannan province of China. In: ASIAN BUFFALO CONGRESS ON SOCIAL ECONOMIC CONTRIBUTION OF BUFFALO TO RURAL AREAS, 5. 2006, Naning. Proceedings. Naning: ASIAN BUFFALO ASSOCIATION, 2006. v.1. p.311-316.

ZEN, Q. K., REN, F. Z., YANG, B. Z., FAN, J. B. Study on protein composition of milk from different buffalo breeds and crossbred progenies. In: ASIAN BUFFALO CONGRESS ON SOCIAL ECONOMIC CONTRIBUTION OF BUFFALO TO RURAL AREAS, 5. 2006, Naning. Proceedings. Naning: ASIAN BUFFALO ASSOCIATION, 2006. v. 1. p. 287-292. 


\section{Dados completos do autor para correspondência:}

Nome completo: Elaine Lopes Figueiredo

Filiação institucional: Universidade do Estado do Pará - UEPA

Departamento: Tecnologia de Alimentos

Função ou cargo ocupado: Professor Assistente I

Titulação: Mestre

Endereço: Av. Tavares Bastos, no 961, Bloco 6, Apt: 103. Bairro: Marambaia. Belém, Pará, Brasil. CEP: 66.615 .005

Telefones para contato: (91) 3243-2117, (91) 8109-2612.

e-mail: lane_figueiredo@yahoo.com.br 